\title{
Fibrillation potentials, positive sharp waves and fasciculation in the intrinsic muscles of the foot in healthy subjects
}

\author{
BJÖRN FALCK, HANNU ALARANTA \\ From the Rehabilitation Research Centre of the Social Insurance Institution, Turku, Finland
}

SUMMARY The extensor digitorum brevis and abductor digiti minimi muscles were examined bilaterally with electromyography in 53 healthy subjects. In $72 \%$ of the subjects either fibrillation potentials, positive sharp waves or fasciculation was seen in at least one muscle examined. These slight, usually symmetric neuropathic signs are believed to be associated with normal aging and to some extent also with external trauma to the nerves and muscles in the distal parts of the foot.

Examination of the extensor digitorum brevis and the abductor digiti minimi muscles is recommended by most textbooks on electromyography. ${ }^{1-5}$ Fibrillation potentials and positive sharp waves, here called denervation activity, as well as fasciculation usually indicate either a local or diffuse neuropathy. In the intrinsic muscles of the foot denervation activity and fasciculations are often encountered in situations where they are not clinically expected, even in healthy subjects..$^{6-8}$ To assess the clinical usefulness of the extensor digitorum brevis and abductor digiti minimi in electromyographic diagnostics, especially in the diagnosis of lumbar radiculopathy, we have studied the occurrence of denervation activity and fasciculation in these muscles in healthy subjects.

\section{Material and methods}

Fifty-three subjects, age range 18-70 years, 25 men and 28 women were examined (fig 1). None had a history or signs of neuromuscular involvement of the lower extremities. Needle electromyography was performed with standard equipment using DISA $13 \mathrm{~L} 49$ concentric needle electrodes. The extensor digitorum brevis and abductor digiti minimi were examined bilaterally. In 20 subjects with

Address for reprint requests: Dr Björn Falck, Peltolantie 3, SF20720 Turku 72, Finland.

Received 11 June 1982 and in revised form 11 February 1983. Accepted 25 February 1983. denervation activity or fasciculation the anterior tibial muscle also was examined on one side (usually the right). In each muscle three separate penetrations through the skin were made and 20 insertions were done at each site. After the final insertion the electrode was left in situ for one minute in each muscle to record fasciculation. Interference pattern also was observed at maximal voluntary contraction, but this was not quantified.

The findings in each muscle were rated as follows:

Denervation activity: grade 0-normal, no fibrillation potentials or positive sharp waves; grade 1-borderline, one positive sharp wave or fibrillation potential; grade 2-slightly abnormality, 2-9 fibrillation potentials or positive sharp waves; grade 3-moderate abnormality, $10-25$ fibrillation potentials or positive sharp waves; grade 4-severe abnormality, fibrillation potentials or positive sharp waves at all insertions.

Fasciculation: grade 0 -no fasciculation; grade 1 -one

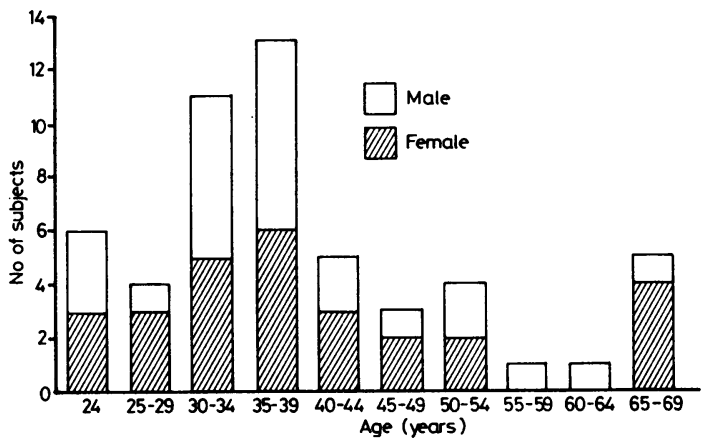

Fig 1 Age and sex distribution of the subjects studied. 
Table Denervation activity and fasciculation of the extensor digitorum brevis and abductor digiti minimi muscles in 53 healthy subjects

\begin{tabular}{|c|c|c|c|c|c|c|c|c|}
\hline & \multicolumn{2}{|l|}{ Grade 0} & \multicolumn{2}{|l|}{ Grade 1} & \multicolumn{2}{|l|}{ Grade 2} & \multicolumn{2}{|l|}{ Grade 3} \\
\hline & $\begin{array}{l}R \\
N\end{array}$ & $\begin{array}{l}L \\
N\end{array}$ & $\begin{array}{l}R \\
N\end{array}$ & $\begin{array}{l}L \\
N\end{array}$ & $\begin{array}{l}R \\
N\end{array}$ & $\stackrel{L}{N}$ & $\begin{array}{l}R \\
N\end{array}$ & $\stackrel{L}{N}$ \\
\hline $\begin{array}{l}\text { Extensor digitorum brevis } \\
\text { - denervation activity } \\
\text {-fasciculation }\end{array}$ & $\begin{array}{l}45(84 \cdot 9) \\
44(83 \cdot 0)\end{array}$ & $\begin{array}{l}46(86.8) \\
39(73.6)\end{array}$ & $\begin{array}{l}1(1.9) \\
3(5.7)\end{array}$ & $\begin{array}{l}0 \\
5(9.4)\end{array}$ & $\begin{array}{l}7(13 \cdot 2) \\
6(11 \cdot 3)\end{array}$ & $\begin{array}{l}4(7 \cdot 5) \\
9(17 \cdot 0)\end{array}$ & $\begin{array}{l}0 \\
0\end{array}$ & $\begin{array}{l}3(5 \cdot 7) \\
0\end{array}$ \\
\hline $\begin{array}{l}\text { Abductor digiti minimi } \\
\text { —denervation activity } \\
\text {-fasciculation }\end{array}$ & $\begin{array}{l}42\left(\begin{array}{c}79.2 \\
22 \\
41.5)\end{array}\right.\end{array}$ & 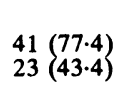 & $\begin{array}{l}2(3 \cdot 8) \\
7(13 \cdot 2)\end{array}$ & $\begin{array}{l}1(1 \cdot 9) \\
6(11 \cdot 3)\end{array}$ & $\begin{array}{r}7(13 \cdot 2) \\
17(32 \cdot 1)\end{array}$ & 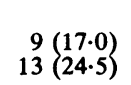 & $\begin{array}{l}2(3 \cdot 8) \\
7(13 \cdot 2)\end{array}$ & 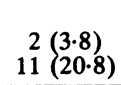 \\
\hline
\end{tabular}

fasciculation potential per minute; grade 2-2-9 fasciculation potentials per minute; grade $3-10-25$ fasciculation potentials per minute; grade 4-more than 25 fasciculation potentials per minute.

\section{Results}

The findings in the extensor digitorum brevis and abductor digiti minimi muscles on each side are given in the table. In only 10 subjects $(19 \%)$ were all four muscles intact. In five subjects (19\%) there were only borderline, grade 1 , abnormalities in one or more muscles. No subject displayed grade 4 denervation activity or fasciculation. Also the anterior tibial muscle was examined on one side in 20 subjects, but none displayed denervation activity or fasciculation. In the majority $(67 \%)$ of the 106 pairs of muscles examined the finding was symmetric. In 20 muscle pairs $(19 \%)$ there was an asymmetry of one grade and in only 15 pairs $(14 \%)$ was the side difference two grades. In no instance was there a side difference of three grades. In the extensor digitorum brevis grade 2 or grade 3 denervation activity on either side was found in seven subjects $(13.2 \%)$ and in the abductor digiti minimi in $11(20.8 \%)$. Grade 2 or grade 3 fasciculation on either side was found in the extensor digitorum brevis in nine subjects $(17 \%)$ and in the abductor digiti minimi the figure was as high as 24 (45\%). There was no correlation between denervation activity and fasciculation in either muscle. On voluntary activation large motor unit potentials with amplitudes over $8 \mathrm{mV}$ were often seen in the extensor digitorum brevis and abductor digiti minimi, as well as loss of motor units. No difference was found between men and women in denervation activity or fasciculation in either muscle. There was a slight trend for an increase in frequency of denervation activity and fasciculation in the older age groups, this was not, however, statistically significant.

\section{Discussion}

In a high proportion (72\%) of healthy subjects either denervation activity or fasciculation was seen in at least one of the intrinsic foot muscles examined. Often these findings were accompanied by large individual motor unit potentials with a long duration and reduced number of motor unit potentials on voluntary contraction. No abnormalities were seen in the anterior tibial muscles examined. The findings indicate a slight neuropathy of the nerves innervating the small intrinsic foot muscles. These findings are in agreement with those of Roselle et al, ${ }^{6}$ who found in $86 \%$ of young adults signs of neurogenic atrophy in the extensor digitorum brevis. Denervation activity in the extensor digitorum brevis was found by Wiechers et $\mathrm{al}^{7}$ in $16 \%$ and by Gatens et $a^{8}$ also in $16 \%$. This is quite similar to our results $(13 \%)$. There is also histopathological evidence of neuropathic changes, fibre type grouping, in the extensor digitorum brevis in healthy subjects. ${ }^{910}$ These findings were limited in young adults and middle aged people to the extensor digitorum brevis, but in old age fibre type grouping was also seen in other muscles, especially in the gastrocnemius.

One possible cause for this type of slight neuropathy is age-related involution of the peripheral nervous system. Pathological changes involving axonal loss and segmental demyelination in peripheral nerves are known to occur in man with normal aging. ${ }^{1-14}$ There is evidence of axonal sprouting and collateral reinnervation occurring in the human peroneus brevis muscle. ${ }^{15}$ Numerous animal studies also indicate age related involution of peripheral nerves, especially in the distal parts of the hind limbs. ${ }^{16-18}$

In our materials we could not demonstrate a clear correlation between the frequency or abundance of denervation activity or fasciculation and age. One reason for this may be the age distribution of our subjects, most of them were in the age groups between $25-45$ years, while relatively few subjects were in the younger and older age groups. On the other hand denervated muscle fibres are probably readily reinnervated by collateral reinnervation. Since there is a dynamic balance between 
denervation and reinnervation of muscle fibres the amount of denervation activity would not be related to the degree of axonal loss. Therefore it is possible that the amount of denervation activity would reflect mainly the rate of age related involution of the peripheral nerves. Quantitative analysis of motor unit potential parameters might yield better correlation with age. Indirect electrophysiological evidence of fibre type grouping is also derived from single-fibre electromyography, subjects over 25 years of age already have increased fibre densities in the extensor digitorum brevis, but not significantly in other muscles before the age of 65 years. ${ }^{19}$

Another factor, which might contribute to the neuropathy, is mechanical trauma to which the intrinsic feet muscles are subject. Guinea pigs reared on a wire mesh floor develop electrophysiological and histological signs of pressure neuropathy in the plantar nerves. ${ }^{20}$ This indicates that external causes could contribute to the distal neuropathy also seen in man.

Roselle $e a^{6}{ }^{6}$ suggested that the neuropathy seen in the extensor digitorum brevis might be caused by pressure exerted by shoes. This view is also supported by Weichers et al $^{7}$ and Gatens et al. ${ }^{8}$ It seems likely that both biological aging and external traumata contribute to the neuropathic changes seen in the intrinsic muscles of the foot.

The findings have important practical implications on clinical electromyography. Slight or even moderate amounts of denervation activity or fasciculation cannot be regarded as an unequivocal sign of pathology in these muscles, especially if the findings are symmetrical. Therefore we usually omit the examination of the extensor digitorum brevis and abductor digiti minimi in clinical EMG examinations. There are, however, some situations in which the examination of these muscles will be relevant: tarsal tunnel syndrome, ${ }^{21}$ anterior tarsal tunnel syndrome $^{22}$ and sometimes also radiculopathies. Finding no denervation activity or fasciculation is of course significant; otherwise it is helpful to compare with the asymptomatic side when marked asymmetry may be clinically significant.

\section{References}

'Buchtchal F. An Introduction to Electromyography. Copenhagen: Scandinavian University Books 1957:43.

${ }^{2}$ Lenman JAR, Ritchie AE. Introduction to Clinical Electromyography. London: Pitman 1970:175.
${ }^{3}$ Goodgold J, Eberstein A. Electrodiagnosis in Neuromuscular Diseases. Baltimore: Williams and Wilkins Co. 1977:220.

${ }^{4}$ Aminoff MJ. Electromyography in Clinical Practice. Menlo Parks: Addison-Wesley 1978:216.

${ }^{5}$ Ludin HP. Electromyography in Practice. Stuttgart: Georg Thieme Verlag 1980:173.

- Roselle N, Bonne A, Heymans W, et al. Activité myoelectrique de muscle pedieux chez des jeunes sujets normaux. Electromyogr Clin Neurophysiol 1971;10:321-9.

${ }^{7}$ Wiechers D, Guyton ID, Johnson EW. Electromyographic findings in extensor digitorum brevis in normal population. Arch Phys Med Rehabil 1976;57:84-5.

${ }^{8}$ Gatens FP, Saeed MA. Electromygraphic findings in the intrinsic muscles of normal feet. Arch Phys Med Rehabil 1982;63:317-8.

9 Jennekens FGI, Tomlinson BE, Walton JN. Data on the distribution of fibre types in five human limb muscles. An autopsy study. $J$ Neurol Sci 1971;14:245-57.

10 Jennekens FGI, Tomlinson BE, Walton JN. Histochemical aspects of five limb muscles in old age. An autopsy study. J Neurol Sci 1971;14:259-76.

" Rexed B. Contributions to the knowledge of the postnatal development of the peripheral nervous system in man. Acta psychiatrica et neurologica 1944;(Suppl 33):1-206.

12 Ochoa J, Mair WGP. The normal sural nerve in man, Part 2 (Changes in the axons and Schwann cells due to aging) Acta Neuropathol 1969;13:217-239.

${ }^{13}$ Lascelles RG, Thomas PK. Changes due to age in the internodal length in the sural nerve in man. $J$ Neurol Neurosurg Psychiatry 1966;29:40-4.

${ }^{14}$ Swallow M. Fibre size and content of the anterior tibial nerve of the foot. $J$ Neurol Neurosurg Psychiatry 1966;29:205-13.

${ }^{15}$ Harriman DGF, Taverner D, Woolf AL. Ekboms syndrome and burning parestesiae. Brain 1970;93:393406.

${ }^{16}$ Sharma AK, Bajada S, Thomas PK. Age changes in the tibial and plantar nerves of the rat. $J$ Anat 1980;130:417-28.

${ }^{17}$ Grower-Johnson N, Spencer PS. Peripheral nerve abnormalities in aging rats. J Neuropathol Exp Neurol 1981;40:155-165.

${ }^{18}$ van Steenis $G$, Kroes $R$. Changes in the nervous system and musculature of old rats. Vet Pathol 1971;8:320 332.

${ }^{19}$ Stålberg E, Trontelj JV. Single Fibre Electromyography. Old Woking: Mirvalle Press Limited, 1979:244.

${ }^{20}$ Fullerton PM, Gilliatt RW. Pressure neuropathy in the hind foot of the Guinea pig. J Neurol Neurosurg Psychiatry 1967;30:18-25.

${ }^{21}$ Mumenthaler M, Schliak H. Läsionen der peripheren Nerven. Stuttgart: George Thieme Verlag, 1977:364.

${ }^{22}$ Krause KH, Witt T, Rose A. The anterior tarsal tunnel syndrome. J Neurol 1977;217:67-74. 